\title{
Historia de la Flora Mediterránea
}

\author{
Angel Enrique Salvo Tierra
}

Probablemente en muy pocas ocasiones hayamos detenido nuestra atención ante la causa inicial del éxito de diferentes culturas mediterráneas durante muy extensos períodos históricos. La existencia de un mar de aguas relativamente calmas para la navegación, lo que favorece el intercambio de conocimientos entre pueblos muy distantes y distintos, no parece una razón exclusiva. Tal vez hoy, cuando nos encontramos en un momento en el que se vive un extraordinario "culto al cuerpo", algo nada inédito en la moda de los distintos pueblos mediterráneos, sea más fácil comprender que en la base de aquel éxito se encontraba una dieta cuyo equilibrio superaba a la de otros pueblos. No en vano, expertos en nutrición reivindican hoy la dieta mediterránea entre las más sanas.

Mientras los pueblos tcutónicos y sajones, basaban toda su alimentación en la caza $y$, en consecuencia, aumentaban considerablemente su contenido en grasa y por ende el nivel de colesterol llegaba a ser muy elevado en personas jóvenes por lo que la esperanza de vida era muy exigua; en los pueblos mediterráneos la utilización del aceite, la combinación de proteínas de carnes y pescados, y sobre todo la utilización de una gran variedad de vegetales, posibilitaba una vida más prolongada. En aquellos pueblos centroeuropeos alcanzar la ancianidad era un beneficio de los dioses, por lo que los consejos de ancianos tenían un valor extraordinario. Sin embargo, entre los mediterráneos dicha escala de valores era más restringida, de manera que el poder político en manos de personas más jóvenes permitía un mayor dinamismo en la sociedad.

La influencia de la dieta en los movimientos históricos y culturales es notable.

El dominio del Islam y sobre todo su edad de oro en torno al Califato de Córdoba va unida a la introducción en la región mediterránea de una mayor variedad de especies vegetales cultivables con origen en el Oriente Próximo, incluyendo desde innumerables especias hasta la naranja o el café de Moka.

Los monasterios no hubiesen jugado el papel cultural medieval a no ser de su magnífica despensa y sobre todo de algo tan trascendental como la utilización de pan de trigo y no de maíz como hacía el vulgo.

La época de los grandes descubrimientos posibilitó el Renacimiento. Muchos de los cereales, verduras y frutas fueron introducidos entonces en los puertos mediterráneos, y sobre todo drogas de muy diferente índole y un tubérculo cuya trascendencia fue posterior. Pese a que pueda parecer irónico, la revolución industrial se debe en gran medida a la patata. Su facilidad de cultivo y su riqueza en hidratos de carbono posibilitaron el mantenimiento nutritivo de los obreros que hicieron posible dicha revolución.

Valgan estos simples ejemplos para ilustrar la aseveración inicial. Pero, sigamos 
profundizando sobre la causa del éxito de las culturas mediterráneas. El siguiente planteamiento sería: ¿por qué el Mediterráneo y no otras áreas?

Los territorios en torno al mar Mediterráneo se benefician de un clima bastante singular, que junto a una historia geológica cargada de eventos, ha modelado una flora tan variada, que hoy es reconocida por los especialistas como una de las reservas genéticas más importantes del globo.

Gracias a la benignidad del clima y a esa diversidad florística que posee la región mediterránea el hombre, aquí asentado desde épocas muy remotas, ha dedicado una parte muy importante de su tiempo y su trabajo al conocimiento de los vegetales y especialmente de su cultivo. Desde entonces cultura y economía han girado en torno al mundo de las plantas.

\section{El clima mediterráneo}

Tal vez porque vivamos bajo su influencia nos parezca vanal definir el clima mediterráneo. Una definición sencilla del mismo sería aquélla que lo reconoce por una estación cálida muy dilatada, o sea un verano caluroso, seco y largo, y una estación lluviosa y de frío moderado.

Esta definición puede verse complicada cuando reconocemos la existencia de un clima mediterráneo en regiones de la Tierra que no son los territorios circunmediterráneos, tales como la costa pacífica del Cono Sur, Sur de Australia y Nueva Zelanda, Sur occidental de Africa y la región californiana. Todas estas regiones presentan en común el estar situadas entre un área desértica y un área de marcado clima continental. Es por ello que el clima mediterráneo hay que entenderlo como la serie de acontecimientos meteorológicos surgidos por el pulso de fuerzas llevadas a cabo entre las corrientes cálidas procedentes de los desiertos y las frías de las áreas de influencia continental.

De la ausencia de un dominio permanente de una de las fuerzas, así como de un equilibrio también permanente, surge una de las principales características de nuestro clima: su inconstancia. Frente a prolongados períodos de sequía surgen otros de precipitaciones por encima de la media.

Además de dicha inconstancia, efectivamente la existencia de una larga estación seca, sin precipitaciones, alternando con otra de frío moderado y que en las áreas costeras raramente va a provocar la formación de heladas, caracterizan este clima bastante singular.

Por todo ello, la flora que actualmente puebla los territorios de clima mediterráneo está adaptada a esta serie de vicisitudes climáticas, siendo de igual singularidad. La estrategia adquirida por dichos vegetales es tan diversa como las diferentes formaciones vegetales a que darán lugar, respondiendo todas ellas a una característica economía hídrica durante la estación seca.

Transformaciones de hojas en espinas, de tallos en órganos subterráneos o la aparición de indumentos diversos sobre los órganos aéreos, son metamorfosis frecuentes. Pero de todas ellas tal vez la "esclerofilia" sea el fenómeno más típico y extendido. Dicho fenómeno, fácilmente apreciable en el alcornoque por ejemplo, consiste en la aparición sobre las plantas de hojas pequeñas y de dura consistencia, lustrosas por el haz y 
frecuentemente pubescentes por el envés; dichas hojas van a gozar de una vida media superior a los dos años, por lo que la planta va a ser perennifolia, no consistiendo por tanto la estación seca en un periodo de reposo total, sobre todo dada la inseguridad de un invierno próximo lluvioso.

\section{Historia de la vegetación mediterránea}

Para comprender cómo ha sido el modelado de la flora mediterránea, al menos en su parte occidental, hasta su composición actual, debemos tomar como punto de referencia el Mioceno (15-10 Ma BP). Este período geológico está caracterizado entre otros eventos, por la disposición de los polos en una ubicación distinta a la actual, de tal manera que las tierras próximas al Mediterráneo quedaban incluidas en su gran mayoría dentro de la zona intertropical. Es obvio por tanto deducir que el clima que por entonces afectaba a este área era lluvioso y cálido, y que la vegetación dominante estaría constituida por formaciones de laurisilva, es decir bosques en los que dominarian plantas de hojas muy grandes, lustrosas y coriáceas, con una cutícula bien desarrollada que ayudaría al fenómeno de criptoprecipitación. Dicho fenómeno consiste en la condensación sobre las amplias superficics foliares del agua, que en forma de vapor formaba las típicas nieblas de estos climas. La condensación del vapor conllevaría a la producción de pequeñas gotas que caerían al suelo y así asegurarian una elevada y permanente humedad edáfica.

Las formaciones vegetales de laurisilva dominarían las tierras perimediterráneas hasta el final del período miocénico, cuando los polos van a situarse en su posición actual. El principal efecto de dicho acontecimiento va a ser la disminución de las precipitaciones y la presencia de un periodo frío, como corresponde a una zona temperada originada por la exclusión de la franja intertropical.

El cambio va a ser lento y se plasma en un retroceso de las formaciones de laurisilva hacia occidente, en donde la influencia de las borrascas atlánticas garantiza la presencia de un importante número de estirpes, y hacia el Sur, en busca de la nueva zona intertropical.

Antes de comenzar a analizar el efecto del siguiente evento es preciso comentar que durante todo este tiempo la alimentación hídrica del Mar Mediterráneo estaba asegurada por un gran paso abierto entre las Cordilleras Béticas, aún unidas al continente africano, y el zócalo continental mariánico, o sea la actual depresión del Guadalquivir.

Los sedimentos aportados por la erosión de ambas partes llevó a la colmatación de esta depresión y también al cierre de la comunicación entre el Atlántico y el Mediterráneo, allá por el Messiniense. El aporte de los ríos que desembocan en la cuenca mediterránea era muy escaso.

Ante este cúmulo de circunstancias, una importante crisis situada cronológicamente hace 6,5 - 5 Ma BP va a cernirse sobre el Mar Mediterráneo, lo que hoy conocemos como "Crisis Messiniense", y cuyos efectos no solo afectarán a dicho mar sino a la flora y fauna que vivian en su seno y a las que poblaban las tierras circundantes.

$\mathrm{La}$ ausencia de un aporte masivo de agua provocó que el Mediterráneo entrara en un rápido proceso de desecación, disminuyendo considerablemente sus niveles, fundamen- 
talmente debido a un efecto colateral de rápida evaporación. Parece ser que el nivel de las aguas descendió tanto que llegaron a establecerse un considerable número de puentes continentales entre Africa y Europa.

Todo esto condujo a que las aguas mediterráneas sufrieran una intensa salinización, tornándose el clima en seco, siendo entonces muy marcadas las diferencias entre máximas y minimas.

Esta crisis aceleró el proceso de migración de los elementos lauroides miocénicos hacia el occidente y al Sur, permitiendo la entrada por oriente de un importante contingente de elementos adaptados a las nuevas vicisitudes climáticas, muy similares a las existentes en la región irano-turánica. Dichos elementos entrarian a través del Norte de Africa e irian penetrando en Europa a través de los diversos puentes continentales, entre los más importantes el establecido en los Estrechos de Messina y, desde luego, el ya preexistente de Gibraltar, quedando interiormente grandes lagos salados.

La Cordillera Tarikide, que unía las penínsulas tingitana y aljibica, se encontraba cada vez más fuertemente presionada por la fuerza de las aguas atlánticas, terminando por ceder y constituir el Estrecho de Gibraltar, hace $5 \mathrm{Ma}$ BP. Gracias a ello el Mar Mediterráneo recobró su nivel normal de agua y con esto la recuperación de cierta normalidad climática.

El resultado florístico de los acontecimientos ocasionados hasta entonces en el Mediterráneo occidental, es la combinación de una cada vez más diezmada flora miocénica con elementos irano-turánicos, así como por elementos propios que van originándose a partir de aquellos ancestros.

Coincidiendo con el inicio de la Era Cuaternaria un decisivo episodio va a incidir sobre el mundo mediterráneo con igual o mayor trascendencia que los anteriores. El globo entero, pero especialmente el hemisferio septentrional, va a sufrir los grandes efectos de las glaciaciones. Como una veintena de grandes oleadas de frío intenso y prolongado van a azotar durante las nueve décimas partes de la Era Cuaternaria la región mediterránea, alternando con intermedios de clima más suave pero en ocasiones también frío y seco, acantonándose la vida en torno a las tierras litorales del Mediterráneo. Como consecuencia de estos acontecimientos, a los elementos existentes en estas latitudes se les va a unir aquellos otros de origen centroeuropeo y fennoscándico, que en sus avances y retrocesos van a originar nuevos elementos endémicos que definitivamente quedarán restringidos en las zonas cacuminales de las grandes cordilleras mediterráneas. De los antiguos elementos preexistentes muchos se vieron forzados a relegarse hacia el sur y otros a desaparecer.

Decisiva influencia ejercerían las glaciaciones sobre los elementos miocénicos que aún quedaban, por su especial sensibilidad a las bajas temperaturas.

Con el retroceso de la última glaciación hace tan sólo 12.000 años, prácticamente queda esbozada la flora y vegetación mediterránea tal como la conocemos hoy.

Ya ante la mirada del hombre, dos nuevos eventos definitorios van a acontecer.

El primero es la formación del desierto sahariano, cuyo impacto va a ser notorio en la distribución de los elementos y en la drástica selección de los existentes, pero fundamentalmente en la definición del clima mediterráneo.

Parece ser, según los datos de que se dispone, que han existido dos grandes momentos en la historia reciente del planeta en que los centros de los continentes, afectados 
posiblemente por unas corrientes térmicas internas, sufrieron una prolongada desecación debido a que el calor emanado por la superficie terrestre disipaba las borrascas. El primero de estos fenómenos debió ocurrir hace unos $12.000-8.000$ años y ejerció su influencia en América del Norte y gran parte de Eurasia central y septentrional. El segundo se inició hace 8.000 años y culminó hace tan sólo 4.000 años, afectando en esta ocasión a Africa y Australasia.

Antes de que esta desecación se dejara sentir en el Norte de Africa, parece ser que la mayor parte de la región estaba tapizada por una vegetación de tipo sabanoide en la que
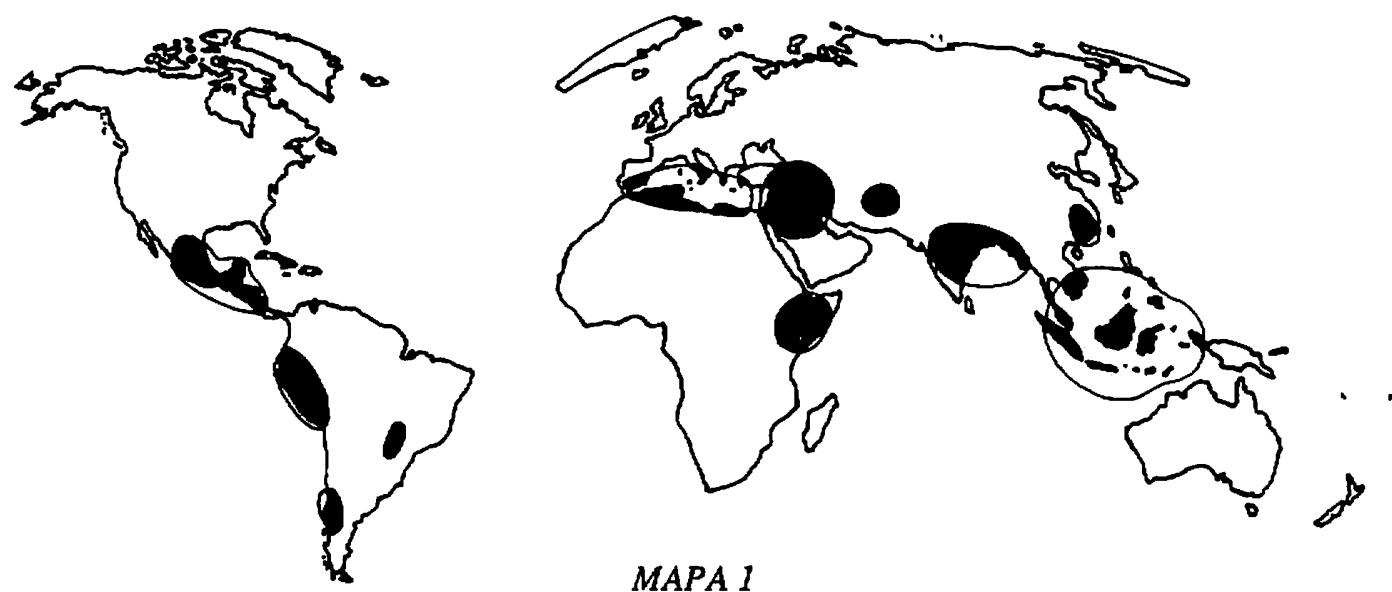

MAPA 1

Areas del planeta con mayor riqueza en recursos genéticos vegetales: centros de máxima diversidad o "Centros de Vavilov".
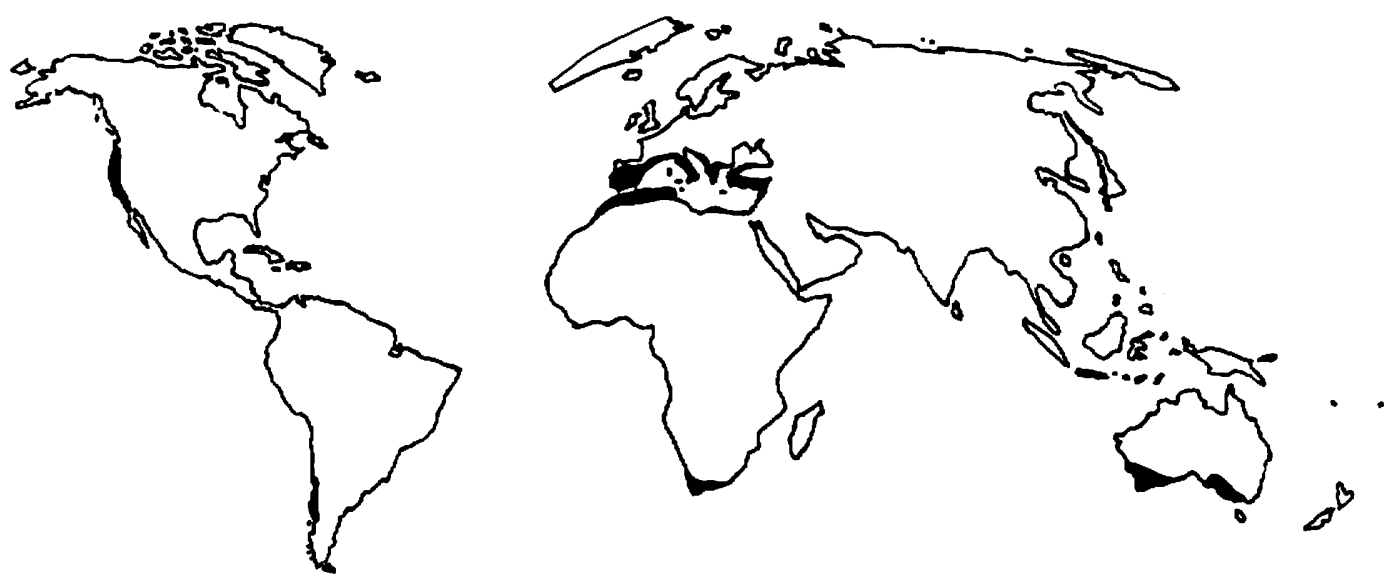

MAPA 2

Zonas del planeta donde se da el clima mediterráneo 
habitaban un gran número de especies animales de interés cinegético, como lo demuestran las pinturas rupestres encontradas en las cordilleras del centro del desierto.

La ubicación de este desierto en las proximidades del Mar Mediterráneo, rompió sobre todo los puentes de unión con la flora tropical, a la vez que aquella miocénica de la que aún permanecían restos en las áreas perimediterráneas de mayor influencia atlántica, vería como sus elementos quedaban reemplazados como relictos a unos cuantos refugios. Pero además, los vientos secos y cálidos procedentes del Sahara provocaron una selección tajante de los elementos montanos en su área directa de influencia.

Sin duda la aparición del hombre ha sido un fenómeno perturbador en todos los ecosistemas terrestres, precisamente por su ubiquismo y capacidad de adaptación a condiciones muy diferentes e incluso extremas. El avance de su cultura y sobre todo de su tecnología ha estado ligada a una progresiva transformación de la Naturaleza. Esta transformación ha sido especialmente significativa a partir de la revolución industrial, que si bien ha supuesto un gran cambio favorable para el hombre en muy diversos aspectos, para muchos otros organismos con los que compartimos el globo el impacto humano ha supuesto una amenaza terrible que en demasiados casos ha llevado hasta la desaparición de determinadas especies.

Es evidente, como deciamos en un principio, que las tierras perimediterráneas han sido y siguen siendo escenario principal de muy diversos aconteceres humanos. Es por ello que su Naturaleza se vea especialmente damnificada por el impacto antropogénico.

Además de los problemas inherentes a la contaminación, residuos urbanos e industriales, etc. que afectan especialmente a la flora del entorno de las urbes, existen dos macrofenómenos que preocupan en gran medida a los especialistas y cuyos efectos hacen presión directamente sobre los elementos más conspícuos de la flora mediterránea: la desertificación y el "síndrome de California".

La desertificación es un proceso típico de las tierras peridesérticas con climas regidos por una estación anual seca, que puede llegar a ser extraordinariamente prolongada a lo largo de un período amplio que incluya sucesivos años, con la total ausencia incluso de precipitaciones. Esta sequia, en cuya responsabilidad parece que pueda intervenir el hombre, es considerada normal en estas regiones, y de hecho aunque los ecosistemas naturales la padecen notablemente, sin embargo dichos sistemas se recuperan a pesar de que la falta de agua sea muy larga en el tiempo. Sin embargo, cuando los ecosistemas se encuentran debilitados por el mal uso del suelo realizado por el hombre, principalmente por una utilización agrícola y pastoril más allá de su capacidad de producción sostenida, entonces se produce un deterioro irreversible que conocemos por desertificación.

Dos mecanismos parece que podrían explicar cómo es la contribución humana al clima de zonas áridas favoreciendo la sequía:

- Por una parte, diversas prácticas como el pastoreo excesivo, la agricultura inapropiada y la tala de árboles y arbustos, provocan una mayor reflexión de la radiación solar, es decir aumentan el albedo. Dichos albedos acrecentados tenderían a disminuir las precipitaciones.

- Por otra parte, en las áreas alejadas de los mares, la mayor parte de las precipitaciones se producen a partir de la humedad del suelo reevaporada. El aprovechamiento irracional del suelo reduciría la capacidad de almacenamiento y en 
consecuencia la evapotranspiración.

En ambos casos, la disminución de la cubierta vegetal perenne entrañaría las siguientes consecuencias en las zonas áridas:

- Aumento del albedo y consecuente reducción del nivel de radiación solar absorbida.

- Temperaturas del suelo elevadas con el correspondiente aumento de la fatiga de los organismos.

- Los materiales más finos del suelo se pierden por erosión y el material orgánico se oxida.

- Reducción de la capacidad de retención de agua.

La desertificación afecta hoy a amplias áreas de la cuenca mediterránea, provocando no solo males irreparables para los ecosistemas, sino para el mismo hombre, quien está asistiendo a la pérdida del valor de un suelo de alta calidad agropecuaria.

El otro macrofenómeno es el que algunos investigadores han dado en llamar "síndrome de California". La benignidad del clima mediterráneo ha llevado consigo a que, como ya vimos anteriormente, la agricultura no sólo se ejerza con especies autóctonas, sino también con especies alóctonas que en muchos casos suelen aclimatarse con relativa facilidad. La introducción de estas especies de interés económico ha supuesto también la de otras sin interés alguno, que una vez aquí se han extendido tan favorablemente como en sus lugares de origen. Estas especies adventícias, en general "malas hierbas" de cultivo, suelen presentar adaptaciones o sistemas estratégicos a veces tan sofisticados que fácilmente desplazan en competencia a las autóctonas.

En California, región de clima mediterráneo y de práctica agrícola similar también a la nuestra, los inventarios florísticos realizados recientemente han puesto de manifiesto que el número de especies vegatales alóctonas ha aumentado considerablemente, casi igualando al de autóctonas. Esta observación que es trasladable a diversas áreas de la región mediterránea, supone la evidencia de pérdida de protagonismo del "pool" génico autóctono frente al alóctono. Si además tenemos en cuenta la agresividad de estas "malas hierbas", es fácil suponer el gran riesgo que muchas de las plantas endémicas mediterráneas, que por endémicas demuestran su alta especialización, corren ante los posibles cambios que sobre el ecosistema pueda ejercer un competidor muy capacitado.

Sucintamente hemos realizado un recorrido por las principales vicisitudes que acontecieron en la región mediterránea y que determinaron el modelado de su flora. Una flora que es hoy rica y diversa, singular y de gran interés para el hombre. Dado su origen variado, existe un gran contingente de elementos relícticos y endémicos que preocupan al científico por cuanto su pérdida supondría la desaparición de un importante material cuya información genética es irrepetible. También vimos al principio como este patrimonio natural ha hecho posible el desarrollo de importantes civilizaciones responsables de la evolución del pensamiento humano. Y así, el deterioro de éste nuestro patrimonio natural, como también pudiera ser del artístico, tan sólo puede suponer la pérdida de una identidad basada esencialmente en su entorno. 